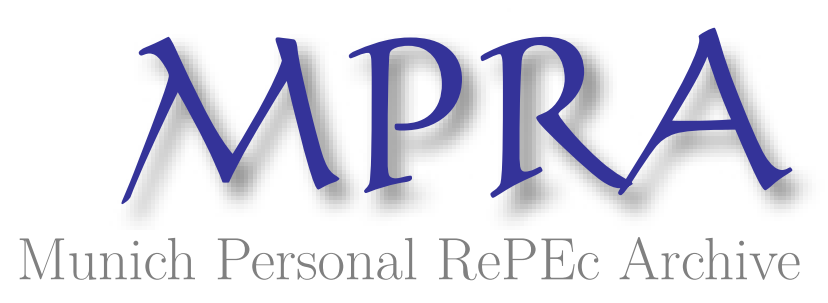

Macro and Micro Spatial Equilibrium

D’Acci, Luca

1 August 2013

Online at https://mpra.ub.uni-muenchen.de/48984/

MPRA Paper No. 48984, posted 09 Aug 2013 13:16 UTC 


\title{
Macro and Micro Spatial Equilibrium
}

\author{
Luca D'Acci
}

$1 / 8 / 2013$

\begin{abstract}
These pages briefly mention the assumption of indifference between residing in different locations which is embodied in spatial equilibrium. Sometimes, for a person, a pure indifference may result, namely gains and costs (monetary or not) are entirely compensated among locations; but sometimes not, and decisions are made on the basis of an overall gain, which implies that locations are not so indifferent for a specific person, even if they appear in equilibrium from a theoretical point of view. The reasoning ends by proposing the Macro Spatial Equilibrium and the Micro (or Subjective) Spatial Equilibrium.
\end{abstract}

Keywords: Cities, Spatial Equilibrium, Urban Economics, Personal Isobenefit Lines, Property Value, Location Decisions, Subjective Spatial Equilibrium.

\section{A brief introduction of Spatial Equilibrium ${ }^{1}$}

"The key theoretical element in urban economics is the idea of a spatial equilibrium: there are not rents to be gained by changing locations. This is a powerful concept that has been the cornerstone for thinking about such key urban topics as housing demand, the impact of transportation on density, and urban growth" (Glaeser 2008, p. 18). It is conceptually comparable with the no-arbitrage principle in finance.

About the origins of spatial equilibrium we cite Smith (1776), von Thunen (1825) and Marshall (1890), which discussed in various terms the role of transport costs.

The beginnings of spatial equilibrium regarding the optimal location of firms can be traced back to the studies of Ricardo (1817), Launhardt (1882) and Weber (1929).

The completion of various theories with the general theory of economic equilibrium was introduced in the thirties by Ohlin (1933), Christaller (1933) and Palander (1935). In the forties it continued in the works of spatial allocation in relation to costs and transport patterns, visible for example in Hitchcock (1941), Kantorovich (1942) and Koopmans (1949).

In the fifties, the spatial equilibrium approach continued with a variety of studies such as those of Isard (1956) and Lefeber (1958), and the spatial price equilibrium of Samuelson (1952). In 1951, Enke was inspired by the laws of Kirchhof ${ }^{2}$ in electronics for a spatial equilibrium model.

The sixties meet other pivotal figures whit Meyer, Kain and Wohl, whose text of 1965 is a milestone of transport economics, and, therefore, in the understanding of urban phenomena related to spatial location.

And yet Losch (1962), von Boventer (1962) and Kuenne (1963) applied elements of economic theory and general equilibrium interregional programming and the theory of spatial location.

We should however wait Alonso (1964), who, in "Location and Land Use," elegantly and powerfully, consolidates the spatial equilibrium models.

From the text of Alonso a vast literature opens up on the spatial equilibrium within cities, mainly connected to the relationship between moving-costs/housing-costs and local amenities/disamenities. This is the heart of spatial equilibrium: inputs and outputs are balanced.

Regarding housing, more centred than Alonso is Muth with his "Cities and housing" of the 1969.

Mills, in his classic article of 1967, and text of 1972, while following the Alonso' spatial equilibrium, completed it by extending the domain.

\footnotetext{
${ }^{1}$ Paragraphs 1, 2 and 3 are basically taken from parts of one of the masterworks of Glaeser: Glaeser 2008.

${ }^{2}$ In an electrical circuit node, the sum of currents flowing in equals to the sum of currents flowing out. Idem for the voltage.
} 
In the seventies, among the greatest contributions we can mention three main figures: Henderson, Quigley and Rosen. Henderson contributed, with a mix of work between the theoretical and the empirical, especially in the analysis of sizes and types of cities (1974). Quigley worked mainly in Housing Economics, referring for example to the heterogeneity housing supply. Rosen is the bridge between Henderson and Quigley (Glaeser 2008). His well-known work on hedonic prices and the spatial equilibrium across space applied the principles of spatial equilibrium in inter-cities comparisons.

The eighties saw a large number of urban economists such as Arnott, Berliant, Bruecker, Ellwood, Gyourko, Helsley, Ioannides, Linneman, Rosen, Small, Tropel, White, White, Yinger, and many others (Glaeser 2008). In the nineties dominates the figures of Krugman - urban economist whose paper of ' 91 is the first full spatial model with agglomeration economies treated as endogenous, opening up a new generation of theoretical models often known as the "new economic geography" - and Fujita.

In our century, Glaeser is certainly distinguished in spatial equilibrium.

There are at least three spatial equilibriums to be taken into account for a comprehensive study of urban phenomena and a general urban model:

1. firms (high incomes require high productivity),

2. builders (high construction costs, or edificatory restrictions, involve high housing prices),

3. workers (higher real incomes are offset by lower local amenities).

Where real income, here, is intended as the difference between the nominal income (wages), and, mostly, housing costs.

These three equilibrium equations determine, respectively, the three following key variables: wages, house prices, population.

In general simplified approximation, we can think of the spatial equilibrium as a compensatory equality throughout the space of the relations among income, prices and amenities.

Spatial equilibrium assumes that these three factors are, under certain conditions, offset against each other when moving from one location to another: high incomes are offset by high prices (housing, cost of living), and/or local negativity (climate, crime, congestion, etc.), and vice versa.

When the study is addressed within a city by comparing the diversity (assumed to be compensatory) between its different urban areas, it is called Spatial Equilibrium Within Cities.

When it is turned to the comparison between different cities, comparing their incomes, costs and amenities, it is called Spatial Equilibrium Across Cities.

Assuming spatial equilibrium, means that high incomes are offset by something negative such as high housing prices and/or low local amenities, and, if it does not, the market (if free) will fix the equilibrium, through a rise in house prices and/or (if free and cheap) in the form of migration (Glaeser 2008).

Incomes are, in part, defined by the interaction between the demand and supply of labour; the latter is formed at the local level, based on individual location choices about where to work and live, while the demand of labour depends on the businesses decisions location.

The individual location choices depend, in large part, on the amenities and local incomes.

Although we have mentioned so far mainly three actors (firms, builders, ordinary citizens, who, with their location choices, take part in the game of spatial equilibrium by three equations whose unknowns are respectively nominal income, housing prices and population), we must not forget the role of politicians and local governments.

\section{Spatial Equilibrium Within Cities}

For spatial equilibrium in its purest and simplest form, we can refer to the AMM model: the Alonso-MuthMills model. Although it considers the residential location choice in the simplified case of a monocentric city, it is perhaps the most successful urban economic model and is a valuable starting point for any study of urban economics.

The actors are the citizens who choose where to live on the basis of distances from the city centre (imagined as place of work too). Their choice is taken by optimizing a utility function assuming an indifference between living in different locations.

Extensions of the model, such as those of Wheaton (1977), Leroy \& Sonstelie (1983), and many others, contemplate different transport systems. Endogenizing the land area choice, we get information about the density (Glaeser 2008). Similarly, endogenizing living spaces (rather than lands), by bringing it into the utility function to optimize, dates back to the Muth's approach (Brueckner 1987). 
We have other examples of extensions by introducing the heterogeneity of incomes as endogenous variables (Glaeser, Kahn and Rappaport, 2008), or by considering the decentralization of jobs (Fujita \& Ogawa, 1982, Henderson \& Mitra 1996 Lucas and Rossi-Hansberg 2002), more realistic than the assumption of monocentric cities on which the original models of Alonso, Muth and Mills are based.

In general, spatial equilibrium models within cities consider income as a constant variable and the spatial equilibrium analysis takes into account mainly the relationship between real estate prices and local amenities as accessibility, social context, green spaces, services, aesthetic quality, pedestrian areas, views, distance from the city center/s, pollution, artistry-historicity, and so on ${ }^{3}$.

\section{Spatial Equilibrium Across Cities}

The fundamental spatial equilibrium across-cities is the model of Rosen-Roback (Rosen 1979, Roback 1982).

As previously mentioned, there are three equilibrium equations underlying the heterogeneity of income, prices, and population density of the city.

The first difference with the spatial equilibrium within cities is the lack of the constancy of income.

The three equilibrium equations are those presented in the previous paragraph.

The within cities highlights the third point (the location choice of the citizen within the city) and considers more or less constant the first two points; the across-cities considers all three points, and looks at their aggregate values (therefore at city level), no longer at the differences among real estate values of different areas within the same city.

Similarly, for simplification and conceptual modelling, does not consider the diversity among different areas of the city regarding commuting costs, and the citizen's choice of location is analyzed not as a choice between living in an area rather than another within the city, but as a choice between living in the city or not, or (if the migration is free and cheap) to live in a city rather than in another.

These choices are based on income, house prices, and amenities that a city offers respectively to the "nocity", or compared to another city.

According to the spatial equilibrium assumption, the three factors (income, prices and amenities) are in compensatory equilibrium between one city and another, and between the city and the no-city.

A key element to keep in mind in these kinds of comparisons are crucial boundary conditions such as varying degrees of freedom - political, economic, cultural, psychological - in migration: Depending on the level of freedom to migrate, an increase in income may reflect both an increase in local productivity as a decrease in attractiveness.

\section{Isobenefit Lines and Spatial Equilibrium}

The Isobenefit Lines approach (MIT Technology Review 2012), offers lines of equilibrium in terms of the benefit that each point receives from the amenities/disamenities present in the city ${ }^{4}$.

\footnotetext{
${ }^{3}$ The results of a hundred case studies in this direction is summarized in D'Acci 2013b (Tab.1).

${ }^{4}$ The Isobenefit Lines approach is limited on equilibrium while evolution must be studied by adding methods such as Statistical Physics and Games Theory (see, i.e., Bellomo, Carbonaro 2011; Bellomo, Piccoli, Tosin 2012). The static use of Isobenefit Lines translates the present scenario of a city into numbers and 3dimensional volumes and personalizes city readings in relation to personal memories, characters and preferences (D'Acci 2013c). In a dynamic pattern, Isobenefit Lines can offer an interactive planimetry above which to put agents who decide where to reside, walk ..., following their own Personal Isobenefit Lines, and interacting with those of the others. Therefore we can simulate the interactions among amenities and agents, in order to obtain, under certain conditions, locations and moving scenarios, as well as estimate the resulted use and enjoyment of amenities and urban points. The static use of Isobenefit Lines may result helpful, i.e., in quantifications and comparisons of city attractions, geometrical morphologies, fair distribution of social benefit, relations between urban quality/amenities and property values. Either in a static or dynamic pattern, when we are outside the Personal Isobenefit Lines contest, in order to quantify the attractiveness of amenities (nice squares, agreeable pedestrian streets, pleasant parks...), we could use the actual relative (see note 5, p.3 in D'Acci 2013a; this note aims to complete note 5 of that paper) number of people using them (no tourists) just if, throughout the city, population density and the relation among cost, time, comfort and distance from each point to each amenity are constant (at least the latter is almost always impossible). We could anyway tempt to estimate the (platonic) attractiveness by keeping in mind the above factors and auto scaling the evaluation process: "We all know that that park is wonderful for the majority of citizens point of view, even if is not so busy because of being rather inaccessible and/or because of being close to a disamenity", or "Even if it is not so easily reachable, it still has visitors in the weekends", or "That park is always full of people, but also because it is very accessible and/or close to several attractive amenities
} 
Calling the positional value the property value given by extrinsic characteristics (not related to the property itself, but to the urban area in which it is located, that means to its amenities/disamenities), its relationship with the Isobenefit Lines is obvious (D'Acci 2013b), and supports the spatial equilibrium assumption according to which a greater real income is offset by something negative, or, in other words, considering the nominal income as a constant, if you choose to live in a very privileged area of the city, real income ${ }^{5}$ decreases because it is inversely proportional to the quality of the area: the greater the area's quality, the greater the positional value, and, therefore, the greater the housing price, and therefore the lesser the real income.

Vice versa a low level of amenities is compensated by an increase in real income.

Steps among isobenefit lines corresponds to steps among urban amenities, that means steps among positional values, that means (ceteris paribus, namely keeping the intrinsic characteristics constant: a same typology, surface, levels, furniture, etc. of the apartment) steps among property values (D'Acci 2013a).

The empirical verification of this equivalence supports the spatial equilibrium assumption within cities.

In a Personal Isobenefit Lines analysis, a step among isobenefit lines corresponds to a step on the personal willingness-to-pay for living there.

The eventual difference between the latter and the Isobenefit Lines (which consider the preferences of the majority of citizens), could mean an economical advantage, or a disadvantage depending on the direction of the divergence: the Preference Gap Gain (PGG).

Advantage, i.e, is when one prefers an area in which usually nobody would like to live (a quite inaccessible point, distant from any services, non touristic, etc.); disadvantage is when this person is obligated (for some reason), to live in an area that she/he does not like but that everyone loves.

In the first case he could pays less for something which for him has a great value, vice versa in the second case.

This is, in some way, the well-known surplus of the customer (Dupuit 1844, Marshall 1890).

Those examples are valid if we consider the income and the commuting cost as a constant and not depending from the area in which the citizen chose/must live. Income in big and/or expansive cities is usually higher than in small/cheap cities, and this is compensated (spatial equilibrium) from the higher housing costs, general living costs and/or some disadvantage (Glaeser 2008). Therefore the examples mentioned can refer to citizens choosing a place inside a same city (that means having the same job), or across cities/places (countryside, cities, villages...) if their job does not change by moving and does not require commuting change (i.e. independent home workers, such as a writer, web designer working online, etcetera).

This reasoning works as long as there is an adequate volume of trade of houses in the areas, in fact, to fix a price, it is enough that there is one person (not the majority) willing to pay that price. This also depends from the time that the seller is willing to wait for selling, and from the ratio between the number of sellers and buyers for that kind of property/land.

Under those conditions, PGG of the person $\mathrm{x}$, can be visualized/measured by overlapping/subtracting the Isobenefit Lines of $x$ (Personal Isobenefit Lines) and the Isobenefit Lines of the majority (the number enough to fix the price for each price-step) of people (Isobenefit Lines).

Also in analysis of spatial equilibrium across cities, Isobenefit Lines may, with due precaution, be a tool of analysis through the comparison of Isobenefit indexes such as the uniformity of the benefit distribution (relative to the urban pleasantness, and/or specific services/amenities one wants to study), their values, the centroid coordinates, and so on.

\section{When Spatial Equilibrium is an equilibrium}

When we talk about firms and builders location decision, the equilibrium is more clear, however, when we talk about citizens personal decision about where spending their own lives, this equilibrium may not be really an equilibrium, because, in this specific case, the main assumption of the indifference, which is on the basis of spatial equilibrium, may fail.

Sometimes if one person chooses to live in $\mathrm{x} 1$ rather than in $\mathrm{x} 2$ (even if, watching the choices of two, or thousands, 'identical' people, $\mathrm{x} 1$ and $\mathrm{x} 2$ appear in a spatial equilibrium, or even if for the same person there is something to lose - money, and/or time, and/or amenities - and something else to gain - money, and/or time, and/or amenities - in both choice of locations), it may mean that, especially when the two (or more)

too". Another possibility is surveying as many citizens as possible asking of the urban points they like and how much they like them. Idem for estimating the elements inside $E$ (D'Acci 2013a).

${ }^{5}$ Reminding that here for "real income" we refer to income minus housing costs. 
alternative location choices involve a very different scenario (living in a 'good' or 'bad' area, in a big or small house, in the city centre or in the periphery, or even outside the city), that person still prefers $\mathrm{x} 1$ to $\mathrm{x} 2$, unless she/he cannot chose ${ }^{6}$, or unless, between $\mathrm{x} 1$ and $\mathrm{x} 2$, she/he chooses by heads or tails.

If $\mathrm{x} 1$ and $\mathrm{x} 2$ result in a spatial equilibrium, this may mean that, i.e. with the same commuting costs, they have different housing costs and different amenities, and that those differences are reciprocally compensative, equivalent: less amenities but cheaper, and vice versa. But equivalent for whom? Equivalent in this case may mean that, in each moment, there is always a person (to fix the price) willing-to-pay, for both, $\mathrm{x} 1$ and $\mathrm{x} 2$, the same different amount of money between them. If this person is the same person (that means that $\mathrm{x} 1$ is in one of her/his personal isobenefit lines while $\mathrm{x} 2$ is in another having a different 'altitude'), then $\mathrm{x} 1$ and $\mathrm{x} 2$ may be (if the 'housing price isolines' well match the personal isobenefit lines) in equilibrium for she/he, and she/he could choose in a 'random' way (unless involving a big change of life scenarios, even if equivalent, and therefore she/he will choose because, at last, she/he realizes anyway a preference) because she/he prefers both scenarios exactly in the same way (indifference); however if the person who is willing-to-pay for $\mathrm{x} 1$ is another person than that one who is willing-to-pay for $\mathrm{x} 2$, and their differences in the willingness-to-pay between $\mathrm{x} 1$ and $\mathrm{x} 2$ do not match each other, they are not in equilibrium for the two persons, even if $\mathrm{x} 1$ and $\mathrm{x} 2$ show different prices (generated when there is always someone willing-to-pay for more): for each personal point of view, the amenities/price in $\mathrm{x} 1$ are not in equilibrium with the amenities/price in $\mathrm{x} 2$. The same example can be proposed by varying amenities and/or housing prices and/or commuting prices.

We imagine the following: ceteris paribus (same local amenities-disamenities, keeping the same job, etcetera), $\mathrm{x} 1$ is a small flat, costing $400 € /$ month and involving a commuting cost of $200 € / \mathrm{month}$; $\mathrm{x} 2$ is a bigger flat, costing $600 € / m o n t h$ and involving a commuting cost of $0 € /$ month. Or, ceteris paribus (same job, commuting costs, $\mathrm{m} 2 \ldots) \times 1$ is at $500 € /$ month and in front of a nice garden, while $\mathrm{x} 2$ is at $400 € / \mathrm{month}$ but without being in front of a nice garden. We imagine person 1 and person 2 in an identical personal situation (economical, family, etcetera) but we see that 1 chooses to live in $\mathrm{x} 1$ while 2 chooses $\mathrm{x} 2$. From an 'external' point of view, $\mathrm{x} 1$ and $\mathrm{x} 2$ may appear in equilibrium, but then, (excluding the cases when 1 and 2 really do not care between $\mathrm{x} 1$ and $\mathrm{x} 2$ ) why does 1 choose $\mathrm{x} 1$ and not $\mathrm{x} 2$, and why does 2 choose $\mathrm{x} 2$ rather than $\mathrm{x} 1$ ? Therefore, from the point of view of 1 and of $2, x 1$ and $x 2$ are not really in equilibrium. Or also, when people move from $\mathrm{x} 1$ to $\mathrm{x} 2$, it could be that they move because they prefer $\mathrm{x} 2$ (scenario) to $\mathrm{x} 1$, rather than because $\mathrm{x} 2$ and $\mathrm{x} 1$ are globally the same therefore moving from $\mathrm{x} 1$ to $\mathrm{x} 2$ is the same. Otherwise: why move?

Inside a same personal isobenefit lines, or between more personal isobenefit lines with the same value ('altitude' in their 3D version), if the personal isobenefit lines perfectly match the 'housing price isolines', there is the purest equilibrium (among different amenities in this case, as commuting and housing costs are supposed constant) and the dweller can be considered under a real equilibrium and therefore could 'randomly' (heads or tails with a coin) chose among different points inside a same benefit value. "A strong part of the isobenefit idea is that we have some bands of equivalence in a city, given by ranges of the isobenefit values. Within those bands, people can move with a very low level of difficulties, reshaping the use of urban space."

A choice between different lines, inside personal isobenefit lines, require a stronger decision process, and, probably, we are not anymore in a easy equilibrium because the result of the decision may imply a very different kind of life, therefore the dweller could have a preference, that means the locations could not be in psychological equilibrium among each other ${ }^{8}$. In fact, while it may be realistic to believe that people, for the same total cost (commuting and house, and, monetizing it, quality) may 'indifferently' choose their own house among a same isobenefit level that themselves feel as iso-benefit, it is a bit harder" ${ }^{9}$ to believe that people choose with a coin (which would assume that they are in perfect indifference and equilibrium and without any kind of reciprocal gain, namely: living in this or in that scenario is exactly the same) between (for example) living in a big house but in a bad area rather than in small house but in a wonderful area, or in the city rather than in the countryside, etc.

\footnotetext{
6 " $[\ldots]$ migrants continue to pour into these cities, in large part because prospects in their native rural communities have grown far worse. In many countries drought and deforestation along with declining commodity prices have left little choice between migration and starvation. "In Sertao", suggests a local saying from that drought-plagued district of Brazil, "one stays and dies or leave and suffers" (Kotkin 2005, p.133).

${ }^{7}$ Pietro Terna private communication (28/5/2013).

8 "The reasons for moving to the periphery seemed self-evident to working-class people, like one Chicago meatcutter who in the 1920s exchanged 'a four bedroom house on the second floor of an apartment house' for 'a six room house with a big yard' in Meadowvale in the far western suburbs" (Kotkin 2005, p.116).

${ }^{9}$ This is an open question which would be interesting to reply by some massive surveys.
} 
Excluding the cases ${ }^{10}$ of moving because you got a higher nominal income and therefore you can afford a higher quality of life (keeping constant your real income at the previous level), or because of personal reasons such as a specific noisy neighbour, or a neighbour's noisy dog, or because you want to follow/join some person living in a different area, or because you divorce, or change job and want to be close to the new work location, or because of being asked to leave by the landlord, etcetera (see chapter 9 of Knox 1995), when one moves because of reasons connected with the positional factor (area quality, amenities, services... of the area), the kind of gain you need to move, is connected with the positional factor (I prefer that area rather than the other, even if at the same cost - including commuting costs), and/or the monetary factor (I prefer saving money at the cost of living in a lower area/housing quality).

Apart from the above cases, as long as you can choose, you always need a kind of gain in order to make the decision to move (chose) from one position to another, otherwise why move ? How chose?

Imagine having $n$ different locations, within or across cities, (and relative scenarios: income, kind of job, quality of environment, etc.) available, and that Ms Rossi lives in one of these $n$ locations: if Ms Rossi is free to move (as well as to not move), as long as she does not move, the $n$ locations are in equilibrium from her point of view. However, if she decides to move it means that this equilibrium is broken, an overall gain appears and at least one scenario among the $n$ is not in equilibrium anymore: Ms Rossi moves.

Imagine now Ms. Verdi, who must move, and chooses, among $n$ locations/scenarios (within or across cities), and she chooses scenario A; and Ms. Rossi who, in the "identical" situation and possibilities of Ms Verdi, chooses scenario B. Therefore, spatial equilibrium says that A and B are in equilibrium.

However, the fact that Ms Rossi and Ms Verdi are in "identical" situations does not allow us to believe that $\mathrm{A}$ and $\mathrm{B}$ are in equilibrium for Ms Rossi, and that $\mathrm{A}$ and $\mathrm{B}$ are in equilibrium for Ms Verdi.

\section{An open discussion}

We open this broad conclusion by quoting a Nobel prize's piece: "All existence seemed to be based on duality, on contrast. Either one was a man or one was a woman, either a wanderer or sedentary burgher, either a thinking person or a feeling person-no one could breathe in at the same time as he breathed out, be a man as well as a woman, experience freedom as well as order, combine instinct and mind. One always had to pay for one with the loss of the other, and one thing was always just as important and desirable as the other" (Hesse, 1930).

Some (or a same person in a specific time of her/his life), would want one thing just as much as another (often conflicting) thing.

When this is the case, we are in the pure indifference embodied in the equilibrium concept.

However, in many personalities (or times in a person life), this lucky/unlucky nature (lucky because polyhedric and offering the chance to absorb a rich variety of feelings and pleasure from a wide fan of scenarios; unlucky because it imposes a perennial indecision and, even after deciding, a perpetual feeling of loss and, sometimes regrets), is absent or more shaded: they know very well what they want, or at least one scenario gives an overall gain against the others, respectively great or small.

When this is the case, we are not anymore in a personal equilibrium.

We still have two cases: when one believes to know what to prefer and to want, and when one does not know it. Nevertheless these cases are beyond the expertise of the equilibrium matters, as well as of these pages.

The brief reasoning shown, may be simply summarized and extended in the following more general concept: everywhere and in any context, we cannot escape from a merciless balanced summation between something to lose and something to gain; the certainty of a low gain or the risk of a high gain; the fizzy city or the picturesque nature; a stressful but glorious, and also monetary rich, career or a monetary poorer, but quieter and intimate life; the reassuring, warm stability or the stimulating adventure; a deep but closed specialization or a holistic but superficial polyhedric nature, and so forth.

Although some lucky person manages to mix conflicting scenarios without the need to live by half-measures, most of us must come to compromises.

Apart from some cases of real indifference, when one can choose and chooses, it means that, even necessarily losing something, the overall gain is positive and not zero; the different scenarios are not anymore in equilibrium for her/his specific own point of view, the equilibrium is broken therefore she/he chooses.

\footnotetext{
${ }^{10}$ In these cases you could really be indifferent (assumption on the basis of spatial equilibrium) between the new place/scenario and the present one.
} 
As long as we can decide, it is doubtful to think that we decide with a coin (because it is indifferent) if to make a family or not; if to find a permanent job and to buy a house or live around the world backpacking; if to start a busy, great, stressful, rich career or lives calmly in our own peaceful corner.

In a spatial equilibrium pattern, these extreme examples may be compared, under certain conditions, to deciding between living in a flat in the city or in a chalet in the mountain; in a beautiful but expensive area or not; in a big house or not, close to the parents and best friends or not; in walking distance from work or not; and many others factors.

In a superb presentation of spatial equilibrium in cities, we read the following clarifying assertions (Glaeser 2008):

"The economic approach to cities starts with the assumption that locations are chosen and that those choices are not entirely irrational. Adults are not randomly sprinkled across space. They select one place over another $[\ldots]$ there are millions of people each year that move from place to place, choosing new locations" (p. 2).

"Individual choice over locations produces the single most important concept in urban or regional economics: the spatial equilibrium. This core insight comes from the idea that if identical people are choosing to live in two different places then those two different places must be offering an equivalent bundle of advantages, like wages, prices and amenities. Essentially, there must be no potential for arbitrage across space" (p. 4)

"The key theoretical element in urban economics is the idea of a spatial equilibrium: there are not rents to be gained by changing locations. This is a powerful concept that has been the cornerstone for thinking about such key urban topics as housing demand, the impact of transportation on density, and urban growth" (p.18).

"When there are some people who are identical and when those people live in more than one area, this means that utility levels must be equal across space" (p. 47).

"[...] the hallmark of urban and regional economics is the spatial equilibrium concept - the idea that people are indifferent across space" (p. 165).

“[...] people can't improve their condition by moving" (p. 205).

In sum, under the following conditions:

I. excluding the cases of a sudden improvement of your nominal income, and the private sphere influence (although it often plays a main, or even the entire, role in the decision process), such as being close to the family and/or friends and/or memories;

II. excluding the cases when you are personally absolutely indifferent among scenarios,

we list the subsequent statements of our reasoning:

A. if you are free to move as well as free to not move:

1. the fact that you don't move matches the spatial equilibrium assumption: you are aware that by moving you cannot overall improve your condition;

2. the fact that you move means that, for some reason, the equilibrium has been broken, and by moving you improve your condition.

a. When you move not because of reasons such as a daily noisy dog, a bad relation with a specific neighbour, etc., the improvement of your condition is connected with spatial and/or real income factors;

B. if you move (either because you must or want to), and if you are free to choose among different scenarios:

1. if identical people choose different places, it doesn't necessarily mean that these places are in equilibrium from the point of view of each specific person.

We imagine lady Tessa and lady Tara: the first with a picturesque nature, the second with a dynamic one.

If lady Tessa chooses a small Italian town with a lovely climate and intimate genius loci, while lady Tara chooses a modern fibrillating megacity, keeping their personal situation and typology identical, for the 
personal point of view of lady Tessa the romantic Italian town and the modern megacity are not in equilibrium; idem for lady Tara, and this may be valid either keeping constant or not their real income in both scenarios.

For all these reasons, it may result convenient to separate between Macro Spatial Equilibrium and Micro Spatial Equilibrium (or Subjective Spatial Equilibrium).

In the latter example, the intimate Italian town and the modern megacity are in a Macro Equilibrium but, for each lady's point of view, the two scenarios are not in a Subjective Equilibrium.

Just if the ladies preferred both scenarios exactly in the same way, the latter would be in a Macro and a Subjective Equilibrium too.

\section{References}

Alonso, W. (1964). Location and land use: toward a general theory of land rent. Harvard University Press.

Bellomo, N., Carbonaro, B. (2011). "Toward a mathematical theory of living systems focusing on developmental biology and evolution: A review and perspectives". Physics of Life Reviews 8 (2011) 1-18.

Bellomo, N., Piccoli, B., Tosin, A. (2012). "Modeling crowd dynamics from a complex system viewpoint". Mathematical Models and Methods in Applied Sciences, Vol. 22, Suppl. 2 (2012).

Brueckner, J. (1987). "The Structure of Urban Equilibria: A Unified Treatment of the Muth-Mill Model". Edwin, W. M. (ed.), Handbook of Regional and Urban Economics, Vol. II, Elsevier, Amsterdam, 821-845.

Christaller, W. (1933). Die zentralen Orte in Suddeutschland (The Central REgions of Southern Germany). Jena.

D'Acci, L. (2013a). Mathematize urbes by humanizing them. arXiv Physics and Society arXiv:1307.3923 [physics.soc-ph]

D'Acci, L. (2013b). "Monetary, Subjective and Quantitative Approaches to Assess Urban Quality of Life and Pleasantness in Cities (Hedonic Price, Willingness-to-Pay, Positional Value, Life Satisfaction, Isobenefit Lines)". Social Indicators Research, February 2013.

D’Acci, L. (2013c). "Hedonic Inertia and Underground Happiness". Social Indicators Research: Volume 113, Issue 3 (2013), Page 1237-1259.

Enke, S. (1951). "Equilibrium Among Spatially Separated Markets: Solution by Ecectric Analogue," Econometrica, Vol.19, 40-47.

Fujita, M., and Ogawa, H. (1982). "Multiple Equilibria and Structural Transition of Non-Monocentric Urban Configurations". Regional Science and Urban Economics, 12(2): 161-196.

Glaeser, E. (2008). Cities, Agglomeration and Spatial Equilibrium. Oxford University Press. New York.

Glaeser, E., Kahn, M., and Rappaport, J. (2008). "Why Do the Poor Live in Cities? The Role of Public Transportation". Journal of Urban Economics, 63(1): 1-24.

Henderson, J. V. and Mitra, A. (1996). "The New Urban Economic Landscape Developers and Edge Cities", Regional Science and Urban Economics, 26(6): 613-643.

Henderson, J. Vernon (1974). "The Sizes and Types of Cities". American Economic Review, 64(4):640-656.

Hesse, H. (1930). Narziß und Goldmund. Fischer, Berlin. Traslation: dshenai.wordpress.com () 2012.

Hitchcock, F. L. (1941). "Distribution of a Product from Several Sources to Numerous Localities," Journal of Mathematics and Physics, Vol.21, 224-230.

Isard, W. (1956). Location and Space-Economy. Wiley, New York.

Kain, J.F., Meyer, R., and Wohl M. (1965). The Urban Transportation Problem. Harvard University Press, MA, Cambridge.

Kantorovich, L. V. (1942). "On the Translocation of Masses," Doklady Adad, Nauk SSR, Vol. 37, translated in Management Science, Vol. 5, No.1 1958.

Knox, P. (1995). Urban Social Geography. Longman, 3rd edition, Singapore.

Koopmans, T. C. (1949). "Optimum Utilization of the Transportation System" Econometrica, Vol.71, 136-146.

Kotkin, J. (2005). The City. A Global History. Phoenix. London.

Krugman, P. (1991). "Increasing Returns and Economic Geography”, Journal of Political Economy, 99(3):483-499.

Kuenne, R. E. (1963). The Theory of General Economic Equilibrium. University Press, Princeton.

Launhardt, W. (1882). "Die Bestimmung des zweckmaĖûigsten Standorts einer gewerblichen Anlage",

("Determining the optimal location of an industrial site"), Zeitschrift des Vereins Deutscher Ingenieure, 26:

105-116.Marshall, A. (1890). Principles of Economics. Macmillian, London. 
Leroy, S. F. \& Sonstelie, J. (1983). "Paradise Lost and Regained: Transportation Innovation, Income and Residential Location". Journal of Urban Economics, 111(2):319-351.

Lefeber, L. (1958). Allocation in Space: Production, Transport and Industrial Location. North-Holland, Amsterdam.

Lösch, A. (1962) Die räumliche Ordnung der Wirtschaft, 3rded. Gustav Fischer, Stuttgart.

Lucas, R. Jr. and Rossi-Hansberg, E. (2002). “On the Internal Structure of Cities”, Econometrica, 70(4): 1445-1476.

Mills, E.S. (1967). “An Aggregative Model of Resource Allocation in a Metropolitan Area”. American Economic Review Papers and Proceedings of the Seventy-ninth Annual Meeting of the American Economic Association, 57(2): 197-210.

Mills, E.S. (1972). Studies in the Structure of the Urban Economy. Johns Hopinks Press, Baltimore.

MIT Technology Review (18 October 2012). Isobenefit Lines Rewrite Rules for Understanding City Life. http://www.technologyreview.com/view/429679/isobenefit-lines-rewrite-rules-for-understanding-citylife/

Muth, R. (1969). Cities and Housing. University of Chicago Press. Chicago.

Ohlin, B. (1933). Interregional and International Trade. Harvard University Press. Cambridge.

Palander, T. (1935). Beitrage zur Standortstheorie (Contributions to Localtion Theory). Uppsala.

Ricardo (1817), On the Principles of Political Economy and Taxation. London: John Murray.

Samuelson, P. A. (1952). "Spatial Price Equilibrium and Linear Programming," American Economic Review, Vol.42, 283-303.

Smith, A. (1776). An Inquiry intoo the Nature and Causes of the Wealth of Nations. Chicago University of Chicago press, Chicago.

Terna, P. (2013). Private communication: 28/5/2013.

Von Boventer, E. (1962). Theorie des raumlichen Gleichgewichts (Theory of Spatial Equilibrium). Tubingen.

Von Thunen, J. (1826). The Isolated State. Carla M. Waternberg (trans.). Pegamon Press, Oxford, 1976.

Weber, A. (1929). Über den Standort der Industrien (On the Location of Industries). Tübingen, Germany: Mohr Verlag.

Wheaton, W.C. (1977). "Income and Urban Residence: An Analysis of Consumer Demand for Location”. American Economic Review, 67(4):620-631. 